\title{
DISINFORMATION TRENDS IN SOUTHEAST ASIA: COMPARATIVE CASE STUDIES ON INDONESIA, MYANMAR, AND THE PHILIPPINES
}

\author{
Emy Ruth D. Gianan \\ Department of Economics, College of Social Sciences \& Development \\ Polytechnic University of the Philippines \\ (erdgianan@pup.edu.ph) \\ DOI: https://doi.org/10.22452/jati.vol25no1.2
}

\begin{abstract}
The past decade saw a changing political landscape in Southeast Asia. From a promising turn towards democracy, marked by episodes of backsliding and authoritarian tendencies, and recently threats of democratic regression and political decay in most parts of the region, have dominated current discourse. Central to these changes is the evolution of information and communications technology, and the ubiquity of social media platforms as sources of news and information, as well as shaping public opinion. The paper looks into three cases in Southeast Asia: online hate along ethnic lines in Myanmar; Duterte populism and broad forms of disinformation in the Philippines; and increasing fake news and online radical Islamism in Indonesia. Trends, common areas of concern, and possible patterns would be gleaned from the case studies; and from there, distil prospects for engagement and better approaches against the growing concern for disinformation in the region. The research recommends that a more concerted and inclusive regional approach would help turn the tide against an increasingly deceived public.
\end{abstract}

Keywords: Southeast Asia, disinformation, communication, social media, democracy

\section{Introduction}

Broad access to information, free speech, and expression are cornerstones of strong and functioning democracies. It goes beyond the procedural definition of the presence of regular, free and fair elections, moving towards the more substantive needs of participation, expression, accountability and transparency, 
and responsible governance. In Southeast Asia, we saw an evolving political landscape for the past decade, with particular concerns on the terrains of public discourse for socio-political issues due to the emergence of new information and communications technologies (NICT). Three Southeast Asian countries had the highest internet and social media penetration rate across the globe in 2015 (Revesencio, 2015; Ericsson, 2014; Nielsen, 2014); and continue to be top users today. The internet, social media platforms, and smartphones are said to have "democratising features": free access, user-friendly interface, and broader means for communication. These platforms enabled people to transcend distance, space, time, and hierarchies to establish networks and nodes of engagement among themselves; and as such have been considered essential elements to pursue more democratic societies (Shirky, 2011). However, alongside progressive actions are equally powerful forces that seek to undermine the culture of democracy in the region. In particular, nefarious plots are advanced against free speech, freedom of assembly and expression, and political dissent (Patten, 2013; Carr, 2015; Palatino, 2014; Woolley \& Gorbis, 2017; Paladino, 2018). As such, the discourse geared towards caution and critical observation on the relationship of NICT and democratisation (e.g. Abbott, 2011; Quintos-de Jesus, 2012; Abbott, 2013; Fuchs, 2014; Tapsell, 2017a).

\section{Problem Statement and Research Objectives}

Southeast Asia has a complex relationship with democracy. Governments in the region utilise several democratic institutions such as elections, multiple political parties, and transitions to power. But these same governments are also keen to use state machineries to repress freedom of the press and speech, stifle dissent, and dismantle peaceful assemblies (Carlson \& Turner, 2008; Kurlantzick, 2014; Palatino, 2014; Freedom House, 2017; International IDEA, 2017; The Economist Intelligence Unit, 2019). Such complex relationship is further emphasised and critically examined with the rise of NICT use as source of information and a platform to shape public opinion (Quintos-de Jesus, 2012; Tapsell, 2017a). Have NICT platforms become tools to aid further democratisation in Southeast Asia? Or has it become an ally of creeping authoritarianism? One aspect to look into is disinformation trends that beleaguer the region.

Amid this context, the research asks an urgent question: what disinformation trends are rising in the region? Numerous country-specific case studies and investigative reports have been released in the past five years shedding light on the underbelly of disinformation across Southeast Asia. One thing is clear, disinformation has undermined democratic institutions in Southeast Asian countries, and will continue to do so in more insidious ways. If 
left unaddressed, Southeast Asian states would become more repressive even under the guise of electoral democracies.

The paper intends to look into both common and differing disinformation trends across the region. It also compares similarities and differences in approaches to disinformation. The objective is to identify and analyse varying practices that may be harnessed to create a stronger and more concerted regional approach against the threat of disinformation.

\section{Methodology}

The research utilised a qualitative method of inquiry. Data for the case studies were culled from news articles and investigative reports on disinformation in Southeast Asia published in the past five (5) years. From here on, a sketch of disinformation trends both common and different across the region was outlined. These secondary sources also provided data on government-driven policies, private sector-led programs, and other solutions to address disinformation. They were also outlined in the study, compared and analysed as recommendations for potential regional solutions to the threat of disinformation.

Three (3) Southeast Asian countries were chosen for the comparative case studies: Indonesia, Myanmar, and the Philippines. These three (3) countries experienced dictatorial rule and embarked on democratic experiments on various periods in modern history. Their experiences offer insights on how democratic societies struggle against the rising tide of disinformation.

Indonesia was placed under dictatorship by military strongman Suharto for almost three (3) decades-dissolution of democratic institutions such as elections, political parties and civil liberties, as well as rampant cronyism and corruption stagnated the archipelago's political and socio-economic development. Since its demise on 1998, Indonesia has observed regular elections and transitions of power, improvements in human development, and an active civil society. The experiment is far from over as the rise of fake news and trolls threaten the country's precarious hold on democracy.

Myanmar offers an incisive look on how new democracies grapple with newer threats to its nascent institutions amid increased NICT use. The world celebrated Myanmar's democratic return in 2011 after almost half a century under a military junta. But the positive outlook was short-lived as the wounds of military oppression and prevalent poverty overwhelmed the new leadership. It also did not help that ethnic wars particularly against the Rohingya Muslim minorities were further emphasised. These provided a linchpin for online feuds in Myanmar, which then translated into offline violence: a clear proof that democracy remains fragile. 
The Philippines is not different from the two other countries. It has also experienced dictatorship for two decades under strongman Ferdinand Marcos. His ouster in 1986 opened the floodgates of democratic rule: regular elections and transitions to power, multiple political parties, and a constitution that guarantees the political and civil liberties of its people. The country's strong and effective civil society is also a model for the region and across the globe. But with a large part of the population mired in poverty, tycoons still raking billions, and politicians abusive of their power, the Philippines remains a development laggard. These deep-seated frustrations along with opportunistic political campaigners who gambled on the strength of social media led to the victory of Rodrigo Duterte in 2016. Since then, the country struggled with the prevalence of fake news and rabid trolling, additional threats to flailing democratic institutions.

The research is divided into several portions. It begins with a literature review: first on Southeast Asia's democratic experiment; followed by the promise and perils of NICT on modern democracies; and finally, the dangers of digital divides and nefarious plots against democratic institutions hatched in online spheres. The second part outlines the case studies for Indonesia, Myanmar, and the Philippines; while the third part fleshes out the findings of the study: common disinformation trends, common approaches to disinformation, and areas for regional efforts to stem the tide of disinformation. These are then analysed in the fourth part of the paper; and from there, recommendations were determined to conclude the study.

\section{Literature Review}

\section{A Culture of Democracy}

Democracies are generally defined by the presence of regular, free and fair elections. For Joseph Schumpeter (1942), it is "a system for arriving at political decisions in which individuals acquire the power to decide by means of a competitive struggle for the people's vote". But for several others, this extends beyond competitive elections: other political institutions should be working to ensure that such a process is not rigged in favour of a singular ruler or captured interests. The unbridled access to information, freedom of expression and dissent, along with associational freedoms of assembly and demonstration are also significant for a functioning liberal democracy (Diamond, 2008; Kane, Patapan, \& Wong, 2008). Without these, people grapple in the dark while powerful interests take on the reins and prey upon the citizens and their resources. Democracy begins to regress once these foundations crumble. 
Southeast Asia has a distinct culture of democracy. They believe in its tenets: the people demand free and fair elections, accountable and responsive governments, and push the envelope for greater rooms for dissent and expression. Civil society organisations (CSOs) are allies, and together they have become strong pillars of democracy in the sub-region. They were able to topple dictators and military juntas, while bureaucratic authoritarianism is overcome by broader participation and dissent from the public. In 1989, only the Philippines was ranked "partly free" by Freedom House, while the rest are "not free". Two decades later, Indonesia is "free", and five out of eleven countries are "partly free", strong evidence for the sub-region's commitment towards democratisation (Freedom House, 2017).

But while Southeast Asian countries continue to hold regular, free and fair elections, and allow the presence of certain CSOs, there remains elements that undermine its democratisation process. Often, dissenting opinion and street protests lead to state crackdown as seen in the Red Shirt-Yellow Shirt demonstrations in Thailand, eventually leading to the reinstatement of military junta. In several parts of Cambodia, Indonesia, and the Philippines, journalists who expose corrupt practices and military leaders who decry various forms of inequalities are either jailed or fatally wounded. Strong governments see these forms of dissent as direct challenges to their leadership and authority; and as such, sowing fear through large-scale show of force to restore order and legitimacy of the regime (Kane et al., 2008). Free expression is assailed and dissent which should be a "natural feature of democracy" is taken away from the agency of the people.

\section{From the Streets to Online Avenues}

The advent of technology created opportunities for seamless communication and connectivity, through the internet and social media platforms. For positivists and technological determinists, these platforms are manna from heaven. The confluence of high-speed internet rise of social media platforms, and the ubiquity of smartphones seemed to answer the need for stronger democracies. They noted how NICT could remove barriers where authoritarian leaders thrive and broaden spaces for public participation in decision-making and collective action (Shirky, 2011). Compared in the 1990s, the sub-region is clearly more connected than ever. Today, millions of Southeast Asians turn to social media platforms for news, entertainment and recently providing spaces for socio-political discourse-penetration in the region is at $44 \%$ in 2015, and Filipinos spend more hours every day versus the average (Revesencio, 2015; Barredo \& Ardevilla, 2018). 
Social media platforms are easy to use as it basically requires a user for a working email address, along with personal details such as name, age, birthday, location, and gender. A password is required to gain continued access to accounts on Facebook, Twitter, and Instagram, to name a few. People who casually watch videos, stream audio/podcasts, or read online stories without intention of creating or curating content may access certain online media platforms without a personal account. Advanced features may be obtained by users willing to pay subscription fees. A user may also choose to create multiple accounts in a single social media platform, usually for selected networks (i.e. to separate private contacts from work-related contacts) or for personal entertainment (i.e. parody accounts or image-building).

These platforms broke away from its initial purpose of becoming a private social network, exclusive to family, friends and colleagues. At the onset, they are virtual networks for people separated by distance and time zones to exchange life updates; share photos, audio or videos of food, cute animals and social events; and ensure people are greeted during their birthdays, anniversaries or milestones. The private is separate from the public. But its growing proximity to human lives and its recent developments on allowing news and editorial articles to be easily read and shared across networks, started to blur the lines between the private and public spheres of human living. Opening social media for greater access and connectivity trumped this traditional structure. Now people can talk and formulate an opinion online, share it with friends, or even debate about it. Boeder (2005) says that such a feature serves as a virtual reincarnation of Jurgen Habermas' public sphere as people are cultivating a culture of exchange and articulates public opinion, which in turn is a valuable component of a democratic society (Habermas, 1989; Benson, 2009).

True enough, social media platforms became vital tools to the political process and thinking of the younger generation. For instance in Indonesia, Johansson (2016) and Molaei (2014, 2015) note that these NICT tools complemented and at certain times substituted for traditional media links, while Susanti (2015) said that Twitter became a primary tool to react immediately on a certain issue or interact with politicians who have online accounts. The authors note that these tools were essential for Joko Widodo, previously Jakarta Governor and currently Indonesian President, to secure popular support and win the national elections (Susanti, 2015; Nugroho \& Syarief, 2012). Singaporeans turn to online memes and pop culture references to wittily comment on pressing domestic socio-political issues (Sreekumar \& Vadrevu, 2013; Vadrevu \& Lim, 2012). This has since contributed to a "surge of interest in using new media platforms for political engagement". Malaysian public officials, on the other 
hand, took advantage of the internet as a means to connect with their constituents (Leong, 2015). And while Malaysian officials took their agenda online, leading political party Barisan Nasional (BN) also saw its political power wane with popular vote rising in 2013 to 51\% (Clarke, 2004, cited in Leong, 2015).

Kushin and Kitchener (2009) already saw the potential of social media platforms to launch socio-political discussions, engage in political debates, and even work together on certain common advocacies or causes. Socio-political discussions have already been happening in the internet; but their study highlighted that social media platforms created greater spaces for these discourses to flourish given the "decreasing cost of internet access... larger populations and new participants into the foray of online political discussion". Its existence pushed the boundaries of setting socio-political agenda, influencing behaviour of voters and constituents, created spaces for participation by demanding greater accountability from the government (Dutton, 2009; Newman et al., 2012, cited in Leong, 2015, p. 50). There is greater information available to different people located in various places and situated in different times. Such differences are overwhelmed by the ease of connectivity, bringing them together online to discuss, debate and collaborate or even negate one another. It is said to be a "new form of egalitarian democratic ideal" (Leong, 2015, p. 50). All of these are hallmarks of democracy, vital for its cultivation and continued evolution. Recently, the United Nations Human Rights Council (2011) enshrined internet freedom and access a form of human right.

The previous discussions point to the ability of NICT to positively affect socio-political discourses by amplifying discussions among people from all walks of life, and eventually generating substantive public opinion for feedback and exchange. But literature also shows an equally compelling picture that affects democracies in Southeast Asia today (Abbott, 2011; Morozov, 2011; Abbott, 2013; Patten, 2013; Sinpeng, 2013; Kurlantzick, 2014; Woolley \& Gorbis, 2017). Monsters that may hijack and utilise these platforms are created to advance nefarious plots. Their adverse actions include the deliberate distortion of established truths, massive manipulation of data, and online shaming. When consolidated in larger volumes, these could undermine the seeds of democracy and prevent positive collective action from taking place. The succeeding discussions flesh these out further. First, digital divide remains a mounting challenge to harbouring the democratising features of the internet and social media platforms towards elevating political discourse and generating concrete political action from the public. Second, powerful vested interests are taking advantage of the internet and social media to skew public opinion towards their benefit and willful creation of ignorance that directly attacks democracy. 


\section{Digital Divides and Bad Ideas}

New forms of technology have promised free and open access to their platforms. But as much as it promises a "flat world", it falls short on the concept of fairness and equality as it does not effectively level the playing field for everyone. Several groups of peoples "are disadvantaged due to their inability to get online". According to Thornton (2002, cited in Boeder, 2005), these modern platforms are highly accessible to people with higher educational attainment and those living in large, urban areas (corroborated in the 2014 Ericsson Mobility Report). Such a situation heightens digital divides among countries; and within societies, it draws the line across socio-economic classes, as it remains an "impediment to a more equitable access to the new media" (Pertierra, 2012, p. 32). Paradoxically, the groups of people who are in dire need of information and access to online resources, usually those who are far from government centres or market hubs, are the ones deprived of internet and social media access. In the 2017 Freedom of the Net Report, the issue of internet access is further compounded by concerns over the degree of internet freedom people enjoy. Wealth generally translates to greater access, but it is not a decisive indicator of free expression, privacy, or increased access to information online.

The internet and social media highlight an essential human need: to interact and collaborate to come up with new ideas and areas for innovation (United Nations Human Rights Council, 2011; Taylor, 2014). Modern technology should serve as a virtual highway that connects people and ideas together, but it cannot fully take advantage of this because access is either too costly or limited to urban centres with already available technology for connections. Further, as shown in the previous illustration, internet freedom is restricted. What could have been tools to strengthen democracies became instruments to retain oppressive governments and perpetuate resources in the hands of the few. This then creates more problems. Limited access is further skewed by recent technological tweaks done in social media platforms. Meanwhile powerful vested interests take advantage of both limited access and their seemingly unlimited resources to further tilt online discussions to their benefit.

Recent algorithms launched in social media platforms create new filters. A certain individual would now mostly be exposed to posts, pages, news, and information based on one's personal preferences. These "filter bubbles" stems from new media companies' efforts to "track the things we like and try to give us more of the same" (Taylor, 2014, p. 131). Examples include predictive texts and engines, as well as recommended sites or pages. These should be harmless, after all they intend to ease our internet use; but in the long-run, it poses dangers on how people think and generate public opinion as they are formulated on the 
basis of things and ideas a person prefers alone, and not through a more astute process that involves debate and criticism. A person who already prefers a certain idea or subscribes to specific worldview would tend not to overthink his/her position on an issue. So, when an unpopular opinion or an insight opposite his/her current stance would suddenly be presented, individuals would see them on a negative light (Kushin \& Kitchener, 2009; Taylor, 2014). On certain times, they would wait for a majority opinion to surface and express the same, for fear of possible isolation (Leong, 2015).

Limited access and filters set on personal preferences may also be factors that contribute to a culture of online shaming and cyber-bullying (Hudson, 2013; Ronson, 2015a, 2015b; Sison, 2015; Madrazo-Sta. Romana, 2015; Raicu, 2016; Vergara, 2016). These circumstances worsen because of mob mentality-the sheer volume of bashers or online attackers would force an individual or groups of people to either shut down their page or become subjects of virtual threats. As much as there are critical thinkers then, they are drowned out by the number of supporters who push for the more popular or most liked stance on issue. Literature and studies have not fully explored how this could be measured and further investigated but suffice to say that these may pose serious threats to free speech and democracy in the long run.

Following this line of thinking, people become lazy engaging in discussions for possible fear of missing out or being singled out. They also fail to validate the materials they read or the information they obtained thinking that if it comes from the internet and shared by many it is true and verifiable. This brings forth the second level of discussion: powerful vested interests are on the move towards skewing online access in their favour. Limited access breeds pockets of information asymmetry, and powerful forces take advantage of these blind spots to fill in the gap and create new information to the detriment of the public. The internet is a powerful tool to validate information, but oftentimes people choose not to use it to their advantage (Fuchs, 2014; Kenyon, 2016).

Ignorance may be observed on the proliferation of "clickbait" storiesmaterials with catchy titles and creative writing which can easily convince people that the information shared is true (Taylor, 2014; Gardiner, 2015; Leong, 2015; these works discuss how "clickbait" relate with "slactivism"). But more recent studies have shown how clickbait stories utilised ignorance to sow disinformation among the people- "fake news" as they call it. Key trends on internet un-freedom now include state-sponsored censors on mobile connectivity and internet discussion and technical attacks against news outlets or opposition leaders (Freedom House, 2017). The same report also notes that internet unfreedom trends may include restrictions on virtual private networks (VPNs), and 
on certain cases there are physical attacks stemming online. The mass appeal of distorted truths coupled with the volume through which it is shared pose serious threats to democracy. Powerful interests, usually governments, employ "architects of networked disinformation" to manipulate online discussions, move them away from controversial topics, or deliberately create propaganda. Some of the strategies used are "astroturfing" or feigning support for the government, bashing or mudslinging to smear government opponents, hacking and spamming through bots, "hashtag poisoning" or flooding anti-government hashtags with irrelevant posts to bury useful information, and mobile connection shutdown (Freedom House, 2017).

\section{Case Studies}

\section{Myanmar: Facebook's Contribution to Disinformation, Hate Speech, and Ethnic Cleansing}

Years under the military junta prevented the people of Myanmar from accessing the internet. It was only in 2013 when the Thein Sein administration broke the state monopoly on the telecommunications industry that people were able to hold mobile phones and surf the web. Prices of SIM card fell from a hundred to a dollar, stores offered cheap China-made smartphones, and the new telecommunications companies offered Facebook use free of data charges. The result is a surge in internet penetration in Myanmar to 18 million users today, and an increase in Facebook accounts made in a matter of days. Facebook served as the new source of information and news for the giddy public $-38 \%$ of users get their daily news from the social media site (McPherson, 2018; Gowen \& Bearak, 2017).

But alongside the flowering of online activity in Myanmar is the parallel increase on hate speech and disinformation against the Rohingya minority in Facebook newsfeeds. The situation is especially alarming as online hate already transitioned towards offline violence (Young, Swammy, \& Danks, 2018; McPherson, 2018; Goldberg \& Diamond, 2019). Hundreds of thousands of Rohingya Muslims have been fleeing to the borders to escape state-led ethnic cleansing and other violent operations launched by angry Buddhist mobs. One should note that even before the online feud on Facebook, there are already tensions between the Buddhist majority and Muslim minority in Myanmar. The government's discriminatory policies, particularly its refusal to grant Rohingya citizenship, have contributed to this growing issue (Albert \& Maizland, 2020). Adding fuel to the fire, ultranationalist religious leaders spoke of hate on their regular preaching to mobilise people against the Rohingyas-an example of which is Buddhist monk Ashin Wirathu. He has since been banned from public 
preaching and has now turned to Facebook to spread the word against Rohingyas (Ortiz \& Rafanan, 2018; McPherson, 2018).

Foreign media companies launched several investigative reports, and they found out that hate speech and disinformation had been brewing as early as 2013. Several civil society groups warned Facebook that their platform could be used to foment ethno-religious tensions between Buddhists and Rohingyas, but the social media company did not budge. In 2017, after Rohingya militants attacked government forces, the state launched clearance operations that saw 25,000 Rohingyas killed and 700,000 more were displaced (Stecklow, 2018; Safi \& Hogan, 2018). A large part of genocide was attributed to hate posts and disinformation campaigns in Facebook, Messenger, and Twitter: Rohingyas were stockpiling arms to destroy pagodas, the minorities were burning their own homes, and news of fabricated jihad were shared at least 9,500 times and received an estimated 3,400 reactions, inciting the aforementioned violence (Young et al., 2018; Safi \& Hogan, 2018; Specia \& Mozur, 2017; Ortiz \& Rafanan, 2018).

An assortment of government, civil society groups, and Facebook attempted several mechanisms to mitigate harm and prevent disinformation from further disintegrating into chaos and violence. Facebook increased its Myanmar language experts from two to a hundred, and even opened up a confidential project with Accenture "Honey Badger" to monitor hate speech and disinformation in Myanmar and across Southeast Asia (Stecklow, 2018). They also deactivated accounts of several known inflammatory offenders, while government pushed for internet shutdown during peak violence (Young et al., 2018; Goldberg \& Diamond, 2019). The measures undertaken were mitigating but does not fully address root causes of the problem. If for anything, it pushed some offending users to find other ways of spreading hate speech-some migrated platforms, while others used multiple accounts. There are no specific undertakings to understand hate speech and disinformation phenomenon in Myanmar fully, and the recent investigative reports have yet to prove if these online operations were supported by more powerful forces aside from some being government sponsored.

\section{The Philippines: Innovative and "Insidious" Ways to Spread Disinformation}

As early as the 2000s, the Philippines took advantage of communications technology to organise protests and movements. Initial evidence points to the use of SMS to launch People Power 2 in EDSA to oust former President Joseph Estrada due to allegations of corruption and moral ineptitude (Pertierra, 2012). This would soon become the template for other rallies organised in Manila and 
other centres across the archipelago (Kurlantzick, 2014). By 2012, social media platforms are starting to gain popularity among Filipinos; but it would only be in 2016 when it was weaponised for election campaigns. President Rodrigo Duterte's popularity and consequent successful bid to the highest position in the land was largely attributed to his savvy social media presence. His team organised groups of grassroots supporters, dubbed as DDS (Diehard Duterte Supporters), across various social media platforms to ensure maximum exposure for their candidate; this even with a meagre social media campaign budget. They were characterised for their crass language and vulgarity-akin to the President's gutter speech and "say it like it is" attitude. Soon enough, news reports would show that a number of these supporters were part of a "keyboard army" paid at least 10 dollars per day to operate fake accounts to show support to Duterte or malign his detractors even after the elections (Freedom House, 2017).

In a seminal ethnographic study done by Ong and Cabanes (2018), keyboard armies are not only confined to Duterte supporters. A number of them were indirectly hired by several other politicians and PR agencies intent on delivering messages skewed towards certain vested interests (Ressa, 2016; Hofilena, 2016; Inquirer Lifestyle, 2016; Almario-Gonzalez, 2017a, 2017b, 2017c; Cabanes \& Cornelio, 2017). As there are no concrete accountability frameworks for political consultancies, politicians and agencies involved in these digital black operations can raise "plausible deniability" for their actions (Ong, Tapsell, \& Curato, 2019). The strategies they employ do not only involve operating fake accounts to drum up support or attack dissenters. There were also deliberate efforts to manipulate public opinion, create propaganda, and "harbour moral compromises: from seeding revisionist history narratives to silencing opponents to hijacking news media attention through artificially trending hashtags". They are called "architects of networked disinformation". Specifically, they are defined as:

Professionalised and hierarchised group of political operators who design disinformation campaigns, mobilise click armies, and execute 'digital black ops' and 'signal scrambling' techniques for any interested political clients... regardless of party and ideology...come from advertising and PR industry, which takes advantage of the unregulated and highly profitable industry of digital political campaigning. (Ong \& Cabanes, 2018)

Architects of networked disinformation (ANDs) are a mix of precarious middleclass individuals and professional elites with varying motivations for 
involvement but are sure to be "complicit with an exploitative system for as long as they gain or maintain power for themselves". A recent study commissioned by New Mandala (Ong et al., 2019) shows how the AND industry expanded to include micro and nano-influencers, alternative news sites, and closed Facebook groups with niche topics or hobbies (21). They compartmentalise their work from moral rationalities and personal stances on issues-engagements are projectbased and side-jobs, hence they are not fully responsible for the impact of their political actions. Disinformation tactics in the Philippines have become more creative, insidious, and more difficult to detect less explicit, more aligned with organic content giving the audience an air of authenticity and spontaneity, and intent on affirming current biases or pre-existing dispositions over several sociopolitical issues (28).

The Philippines has a relatively good grasp of ANDs' existence, its political economy, and their impact on socio-political discourse. Journalists and civil society leaders claim that the main source of fake news and disinformation is the government (Wang, 2018). While all these are true, the studies also note how disinformation are products of deep-seated frustrations of ordinary Filipinos from democratic institutions and their reliance to social media for news and information. This has prompted several agencies particularly mainstream media companies, online news platforms, and several academic institutions to work towards improving media literacy, fact-checking daily news and government statements, and urging social media companies to take decisive action against disinformation. There is also a general agreement that blacklisting, and exposition of fake accounts do not address the underlying causes of disinformation, and so would laws seeking to take down controversial content and penalise social media companies akin to what Germany did (Ong \& Cabanes, 2018). Taking in the Philippine context, these actions could just easily be converted into class warfare (e.g. educational backgrounds of influencers, "disente" narrative) or a witch hunt.

\section{Indonesia: Exploitation through "Berita Hoax" and Fake Twitter Account Factories}

For Indonesia's first-time NICT users, Facebook is the internet. People turn to the social media platform for the latest news and information. When news broke out of fake news factories during the 2017 gubernatorial race in Jakarta, the government scrambled for mechanisms to mitigate the onslaught of disinformation. Offenders were caught, but the fight has yet to be won.

Saracen is an online syndicate paid to undertake covert content creation operations clearly for profit. They charge at least 10 million rupiah to publish 
fake news against an individual or a group of people. According to reports, "buzzer teams" or "pasukan khusus" (special forces) are required to post content 60 to 120 times per day. They are fed with hashtags to promote and use Googlegenerated display photos; while some of them create at least five accounts each for Facebook and Twitter, and one Instagram account. They were paid 280 US dollars per month and are even housed in luxury homes to make sure they complete the job. They also hire "journalists" tasked to write malicious articles as directed by their clients, and then posted in various Saracen Facebook pages and affiliated accounts to multiply its reach. Saracen owner Jasriadi said he hacked 150,000 accounts, lower than the estimated 800,000 accounts affiliated to the online syndicate. Cyber armies were utilised by Chinese-Christian politician Basuki Tjahaja Purnawa, also known as "Ahok", to boost his 2017 re-election bid-they posted hateful comments that fuelled religious and racial divisions online and culminated in Islamic rallies on the streets. Ahok's opponents were not deterred, and an opaque online movement called Muslim Cyber Army launched counterattacks to spread racist and hardline Islamic ideas designed to turn Muslim voters against the re-electionist (Chan, 2017; Soeriaatmadja, 2017; The Straits Times, 2018; Lamb, 2018).

Disinformation in Indonesia is deep-seated, primarily because of the public's mistrust for mainstream media. They are also known to trust information coming from personal ties compared to those sourced from "official" information streams (Soeriaatmadja, 2017; Tapsell, 2017b, 2018). It also did not help that schools have little contribution to digital literacy activities, even removing ICT lessons from the curriculum and replaced by "Bahasa Indonesia, nationalism and religious studies". Several approaches were instituted to address disinformation, as noted in the article. The Jokowi administration created an anti-hoax coordinating body and a special police unit dedicated to cracking down on fake news factories. Meanwhile, the Indonesian press council created verification links as a means of discerning wrong information in the web; Facebook had also setup its office in Jakarta. Cyberspace laws are also in force, albeit more oppressive and invasive (Chalk, 2019). Scholars and civil society leaders believe that the current approaches do not solve the problem as it increases censorship to free speech, which in turn further blocks information vital for people to form genuine political opinion. Rather, they are exposed to more propaganda from the government. Media literacy activities are seen to help, along with strengthening independent and reliable information sources from the local and foreign media, and civil society (Soeriaatmadja, 2017; Tapsell, 2018; Chalk, 2019). 


\section{Results and Analysis of Findings}

Based on the case studies, I find three major trends or issues common among the three Southeast Asian countries: (1) glaring digital divide; (2) income inequalities as exploitative opportunities for the disinformation industry; and (3) deep-seated narratives serve as bases for disinformation. For solutions, I also find three general categories: (1) government-driven efforts, (2) private sector approach which includes social media and mainstream media companies, academic institutions and think tanks, and civil society groups, and (3) possible innovative or good practices seen from the current undertakings against disinformation. I end this section with recommendations based on the practices done by the countries utilised in the case studies.

\section{Common Disinformation Trends}

\section{Glaring Digital Divide}

Aside from urban, educated middle class sections, NICT access broadened to include those living far from the capital and urban areas as well as those with relatively lower incomes. In societies repressed by military juntas like Indonesia and Myanmar, there was a sudden surge of internet users in the last decade. This is largely attributed to ingenious sales innovations done by telecom companies to deepen penetration and increase local sales-smartphones come equipped with social media applications like Facebook and Twitter, and in some cases, Facebook can be used free of data charges. First-time users equate Facebook to the internet and serves as the go-to source for daily news and information. The cheap deals are just one part of the equation: these three countries also suffer from poor internet infrastructure and slow internet connections. With Facebook as an easy app to access, no wonder the public have become overly reliant to the platform in a short span of time. The digital divide remains rooted in socioeconomic cleavages, but it also important to note that poor public service delivery in the form of bad internet connection exacerbates the issue.

\section{Income Inequalities as Exploitative Opportunities for the Disinformation Industry}

Elites take every opportunity to exploit blind spots to advance vested interests. In developing countries like Indonesia, Myanmar, and the Philippines, the loopholes are obvious: weak regulatory framework for campaigns and information disclosure, glaring digital divide and the public's penchant for clickbait stories (i.e. shock value, digestible content), and difficulty of finding decent-paying jobs. The growing disinformation industry turned these 
inequalities into opportunities to expand their reach - the effects are disastrous to democratic institutions. Weak regulatory frameworks for campaigns and information disclosure allowed Ad and PR agencies to tweak existing rules, experiment on message delivery, and establish networks that seed manipulated content. Examples of these exploitative works include the establishment of "fake news factories" in Indonesia and professionalised political operators that design disinformation campaigns in the Philippines (note: they are collectively called "architects of networked disinformation"). They embed controversial political messages in organic content to make it authentic and easier to share across the online sphere. Myanmar has yet to see if hate speeches are driven by hierarchised forces. Right now, reports reflect that they are grassroots-based and organised according to ethno-religious affiliations.

Disinformation has also evolved into a lucrative industry-as shown in the cases of Indonesia and the Philippines, buzzer teams and ANDs are highly paid with additional perks and benefits (e.g. housing, free food and so on). Its project-based and covert nature also offers opportunities for workers to engage with other forms of employment-for some, it serves as additional sources of income, while others use "normal" jobs as cover for possible stigma received by "trolls". Compared with labour-intensive and desk jobs, AND work is relatively easy and manageable: create alternate accounts, post crafted statuses, like or share related content, help "trend" a hashtag. If the harsh realities of unequal societies remain unaddressed and unabated, disinformation work would continue to be an enticing endeavour for people looking for a means to live and survive.

\section{Deep-seated Narratives Serve as Bases for Disinformation}

The problem of disinformation does not begin and end within the online realm. As reflected in the case studies, it is deeply rooted in local cultural practices, distrust on democratic institutions such as the media and elected governments, and long-standing social tensions. People in the societies studied find personal ties as reliable sources of information compared to "official" information streams: in Indonesia, this is rooted on information as "gossip", while in Myanmar, "rumours" and "teashop" discussions are foundations for Facebook engagements, and in the Philippines, information and stances on issues must be confirmed by friends or reliable personalities. In itself, these practices should not be bad, but because the issue is tied with the two previous discussions, it then becomes problematic.

The burden to discern facts from fabricated information does not solely lie on the people. As observed in the three case studies, the public distrust 
"official" information sources like media companies and the government. In Indonesia, there is a $67 \%$ distrust rating for media, $45 \%$ for political parties, and $55 \%$ for the parliament-clearly, the people find it difficult to believe institutions ruled by oligarchic interests. The failure of previous Filipino leaders - educated, middle class, "disente" - to push forward meaningful reforms against poverty and inequality disillusioned the "masang Pilipino". The internet served as a platform to air and validate these grievances, creating a powerful backlash against establishment forces. Long-standing experience under military rule made Myanmar wary of "unseen powers [are] working in the shadows to control the levers of power".

Political histories also lend important insights to understanding the issue at hand: the disinformation industry did not only exploit socio-economic inequalities, they also preyed on existing tensions to heighten social divisions. This refers to ethno-religious divides-Buddhists versus Rohingya Muslim minority in Myanmar, and Chinese-Christian versus local Muslims in Indonesia; while in the Philippines, the divisions are more class-based - "disente" against the "masa", the educated middle class against poor, frustrated ordinary Filipinos. In the words of Ong et al (2019), disinformation does not occur in a vacuum - what happens online are reflections and extensions of what has long been brewing offline.

\section{Common Approaches to Disinformation}

\section{Government-driven Mechanisms}

The state uses its police powers to regulate and censor information they find controversial and detrimental to their political legitimacy. Several European countries embarked on censorship and punitive measures against release of fake information, and soon some Southeast Asian countries are following suitIndonesia, Malaysia, and Singapore, the Philippines mulls its adoption. In Indonesia, Saracen and Ahok were jailed, while Myanmar has turned to harsher options, government crackdown and "clearing operations" against the Rohingya Muslims. They also prevented ultranationalist preachers from public speaking, but this only pushed them to find an audience online. In the Philippines, there is no explicit cyber censorship laws, but the recent attacks and even drug allegations against known opposition leaders are already benign examples of government crackdown. On all these countries studied, governments have special bodies tasked to undertake anti-disinformation campaigns: an anti-hoax coordinating body and special police unit in Indonesia, a technology consultant in Myanmar, and a new Department for ICT in the Philippines. Governments also have strong online presence and are actively engaging the public through 
advisories, videos of government programs and actions, and regular coverage of press conferences and official statements. Strong-handed approaches often do not lead to desired outcomes, and in these cases, ANDs just find innovative ways to spread disinformation as soon as the government cracks down on them.

\section{Efforts from the Private Sector}

These include actions undertaken by social media and mainstream media, academic institutions, and civil society groups. Facebook has expanded its reach in Southeast Asia-from distant operations in their Dublin headquarters to establishing an office in Jakarta, expanding Burmese speakers to understand content coming from Myanmar users, and coordinating with Filipino media companies with regard to monitoring fake news online. They have also set up Project Honey Badger with Accenture during peak violence caused by online hate speech in Myanmar in 2017. Mainstream media companies and online media firms particularly those in the Philippines embarked on fact-checking missions to improve online content and in the process restore credibility. There were also efforts to fully understand the political economy, motivations, and dynamics of disinformation. The Philippines has already produced two comprehensive studies on ANDs, Myanmar has been the site for foreign media investigative reports, while in Indonesia initial analysis of media power and the digital revolution have been made. There were also media literacy efforts, some through inclusion in school curricula, while others are civil society led.

\section{Possible Innovative Solutions to Disinformation}

In all three countries, disinformation contributed to a region-wide regression from democracy as pointed out in the 2014 analysis offered by Kurlantzick. Amid these challenges, there are novel efforts to keep up with disinformation with the hopes of curtailing its adverse impact and underway, strengthening already weak democratic institutions in these societies. Among the three, the Philippines has a stronger grasp of the disinformation problem. Their strength lies on initiatives to fully understand the political economy of disinformation and AND motivations as basis for evidence-based actions against the problem. The next step is to reach political chambers and motivate the government to really take action; for instance, revising outdated portions of campaign finance laws, encouraging ad and PR agencies to strengthen self-regulation against unfair and unethical practices, and increasing efforts for media literacy. Indonesian Press Council begun practices of monitoring disinformation through verification links; the Philippines is also doing this in coordination with Facebook-both are good foundations to improve the health of information disseminated online. 


\section{Regional Efforts Against Disinformation}

The discussions above offer windows for region-based efforts to address disinformation. Individual, domestic efforts are good foundations, but they can be expanded to help other Southeast Asian countries improve their actions and learn from what has already been accomplished by their neighbours. In particular, I suggest the creation of a network of independent and reliable news and information sources across Southeast Asia. The region can already build on ASEAN press corps or organisations such as the Southeast Asia Press Alliance (SEAPA), New Naratif, Asia Democracy Network, and the Southeast Asia Freedom of Expression Network (SAFENet). They can establish nodes of information sourcing, fact-checking, and monitoring of disinformation. This is also helpful as several local journalists are afraid to speak up or undertake projects to monitor disinformation due to security concerns and fear for the safety of their lives and loved ones (e.g. Cambodia, Myanmar, and Laos).

Second, I also suggest that region-wide studies on disinformation particularly fleshing out trends and common issues, as well as comparison of approaches be brought to a larger audience. Right now, individual country studies are undertaken, or foreign media journalists have been taking the cudgels to understand terrains of disinformation in the region. Perhaps with the help of academic institutions, regional think tanks and research groups, we can come up with more comprehensive understanding of how disinformation is taking root in the region. These would also offer opportunities to find solutions or approaches rooted in local contexts. Finally, continued vigilance and push for media literacy should be undertaken across the region. ASEAN can take the lead on this, but also in placing stronger pressure on technology and social media companies to strengthen their algorithms and monitoring mechanisms for disinformation.

\section{Conclusion}

The internet and social media platforms have indeed become new public spheres where socio-political discourses take place. However, the case studies have proven that NICT is plagued with disinformation and other nefarious plots aimed at disempowering democratic institutions. Common issues among the three countries include the following: glaring digital divides; income inequalities as exploitative opportunities for the disinformation industry to thrive; and deepseated narratives particularly those on the offline realm transcend online platforms and become bases for insidious disinformation. There were efforts to address these issues: government-led efforts play on their strongman role and often do not lead to desired outcomes. In several cases, the government itself supports political operators that spread disinformation and is the source of 
propaganda. Efforts from the private sector such as social media and mainstream media companies, academic institutions, and civil society groups, as well as ordinary citizens are important accountability mechanisms to effectively address disinformation. The initial innovative practices done in the three countries offer beacons of hope that eventually disinformation and its accompanying problems would be overcome. In the end, region-wide collaborative efforts are equally important endeavours to address disinformation. Three recommendations were offered by the end of the study: create a network of independent and reliable news sources across Southeast Asia, undertake regional studies on disinformation, and stronger ASEAN role in advocating for media literacy and pressuring tech and media companies to shape up against disinformation.

\section{References}

Abbott, J. P. (2011). Cacophony or Empowerment? Analysing the Impact of New Information Communications Technologies and New Social Media in Southeast Asia. Journal of Current Southeast Asian Affairs, 30(4), 3-31.

Abbott, J. P. (2013). Introduction: Assessing the Social and Political Impact of the Internet and New Social Media in Asia. Journal of Contemporary Asia, 43(4), 579-590.

Albert, E., \& Maizland, L. (2020, January 23). The Rohingya Crisis. BackgrounderCouncil of Foreign Relations. Retrieved from https://www.cfr.org/backgrounder/rohingya-crisis

Almario-Gonzalez, C. (2017a, January 20). From games to social media: The evolution of trolls. ABS-CBN Online. Retrieved from https://news.abscbn.com/focus/01/20/17/from-games-to-social-media-the-evolution-oftrolls

Almario-Gonzalez, C. (2017b, January 20). Unmasking the trolls: Spin masters behind fake accounts, news sites. ABS-CBN Online. Retrieved from https://news.abs-cbn.com/focus/01/20/17/unmasking-the-trolls-spinmasters-behind-fake-accounts-news-sites

Almario-Gonzalez, C. (2017c, January 23). Unmasking the trolls: Countering attacks in social media. ABS-CBN Online. Retrieved from https://news.abs-cbn.com/focus/01/23/17/unmasking-the-trollscountering-attacks-in-social-media

Barredo, J. M. B., \& Ardevilla, J. S. P. (2018, February 14). The Curious Case of Vox Populi 2.0: ASEAN's Complicated Romance with Social Media. Heinrich Boll Stift Southeast Asia. Retrieved from 
https://www.boell.de/en/2018/02/08/curious-case-vox-populi-20-aseanscomplicated-romance-social-media

Benson, R. (2009). Shaping the Public Sphere: Habermas and Beyond. American Sociology, 40, 175-197.

Boeder, P. (2005). Habermas' heritage: the future of the public sphere in the network society. First Monday, 10(9).

Cabanes, J. V. A., \& Cornelio, J. S. (2017). The rise of trolls in the Philippines (and what we can do about it). In N. Curato (Ed.), A Duterte Reader: Critical Essays on the Early Presidency of Rodrigo Duterte (pp. 233-252). Quezon City: Ateneo de Manila University Press.

Carlson, M., \& Turner, M. (2008). Public Support for Southeast Asian Democratic Governance. Asian Journal of Political Science, 16(3): 219-239. doi: 10.1080/02185370802504076.

Carr, N. (2015, September 2). How Social Media is Ruining Politics. Politico. Retrieved from http://www.politico.com/magazine/story/2015/09/2016election-social-media-ruining-politics-213104

Chalk, W. (2019, April 8). Indonesia's Elections Face a Disinformation Crisis. Policy Forum. Retrieved from https://www.policyforum.net/indonesiaselections-face-a-disinformation-crisis/

Chan, F. (2017, September 17). Indonesian Police Uncover 'Fake News Factory'. The Straits Times. Retrieved from https://www.straitstimes.com/asia/seasia/indonesian-police-uncover-fake-news-factory

Clarke, J. (2004). Democracy and New Communication Technology: The Asian Struggle. In S. Gan, J. Gomez \& U. Johannen (Eds.) Asian Cyberactivism: Freedom of Expression and Media Censorship. Singapore: Friedrich Naumann Foundation and Journalism and Media Studies Centre, University of Hong Kong.

Diamond, L. (2008). The Spirit of Democracy: The Struggle to Build Free Societies. New York: Henry Holt and Company.

Dutton, W. H. (2009). The Fifth Estate Emerging through the Network of Networks. Prometheus, 27(1). 1-15. DOI: 10.1080/08109020802657453

Ericsson. (2014). Ericsson Mobility Report: Southeast Asia and Oceania. Retrieved from https://www.ericsson.com/assets/local/news/2014/6/regional-appendicessea-final-screen.pdf

Freedom House. (2017) Freedom on the Net 2017: Manipulating Social Media to Undermine Democracy. Retrieved from https://freedomhouse.org/

Fuchs, C. (2014). Social Media and the Public Sphere. TripleC, 12(1), 57-101. 
Gardiner, B. (2015, December 18). You'll be Outraged at How Easy It was to Get You to Click on this Headline. Wired. Retrieved from http://www.wired.com/2015/12/psychology-of-clickbait/

Goldberg, J., \& Diamond, C. (2019, June 25). Myanmar Cuts Internet to Rakhine State Amid Unrest. The Guardian. Retrieved from https://www.theguardian.com/world/2019/jun/25/myanmar-cutsinternet-to rakhine-state-amid-unrest

Gowen, A., \& Bearak, M. (2017, December 8). Fake news on Facebook Fans the Flames of Hate Against the Rohingya in Burma. The Washington Post. Retrieved from

https://www.washingtonpost.com/world/asia_pacific/fake-news-onfacebook-fans-the-flames-of-hate-against-the-rohingya-inburma/2017/12/07/2c1fe830-ca1f-11e7-b506-8a10ed11ecf5_story.html

Habermas, J. (1989). The Structural Transformation of the Public Sphere. Cambridge, Massachusetts: MIT Press

Hofilena, C. F. (2016, October 9). Fake Accounts, Manufactured Reality on Social Media. Rappler. Retrieved from https://www.rappler.com/newsbreak/investigative/148347-fake-accountsmanufactured-reality-social-media

Hudson, L. (2013, July 4). Why you should Think Twice Before Shaming Anyone on Social Media. Wired. Retrieved from http://www.wired.com/2013/07/ap_argshaming/

Inquirer Lifestyle. (2016, August 28). Confessions of a Troll. Inquirer Online. Retrieved from https://lifestyle.inquirer.net/236403/confessions-of-a-troll/ International IDEA. (2017). The Global State of Democracy: Exploring Democracy's Resilience. Stockholm: International Institute for Democracy and Electoral Assistance (IDEA).

Johansson, A C. (2016, December). Social Media and Politics in Indonesia. Stockholm School of Economics Asia Working Paper No. 42. Stockholm China Economic Research Institute. Retrieved from https://swopec.hhs.se/hascer/papers/hascer2016-042.pdf

Kane, J., Patapan, H., \& Wong, B. (Eds.). (2008). Dissident Democrats: The Challenge of Democratic Leadership in Asia. New York: Palgrave-Macmillan

Kenyon, G. (2016, January 6). The Man Who Studies the Spread of Ignorance. BBC Online. Retrieved from http:// www.bbc.com/future/story/20160105the-man-who-studies-the-spread-of-ignorance

Kurlantzick, J. (2014, May 28). Southeast Asia's Regression from Democracy and Its Implications (Council on Foreign Relations Working Paper). New York: Council on Foreign Relations. Retrieved from 
https://www.cfr.org/report/southeast-asias-regression-democracy-andits-implications

Kushin, M. J., \& Kitchener, K. (2009). Getting Political on Social Network Sites: Exploring Online Political Discourse on Facebook. First Monday, 14(11), 115.

Lamb, K. (2018, March 13). Muslim Cyber Army: A 'Fake News' Operation Designed to Derail Indonesia's Leader. The Guardian. Retrieved from https://www.theguardian.com/world/2018/mar/13/muslim-cyber-army-afake-news-operation-designed-to-bring-down-indonesias-leader

Leong, P. (2015) Political Communication in Malaysia: A Study on the Use of New Media in Politics. Journal of Democracy, 7(1), 46-71.

Madrazo-Sta. Romana, J. J. (2015, July 6). Smart Shaming and Our Pinoy Culture of Anti-intellectualism. GMA News Online. Retrieved from http://www.gmanetwork.com/news/story/517026/scitech/science/smartshaming-and-our-pinoy-culture-of-anti-intellectualism

McPherson, P. (2018, August 31). Myanmar Army Fakes Photos and History in Sinister Rewrite of Rohingya Crisis. The Guardian. Retrieved from https://www.reuters.com/article/us-myanmar-rohingya-photosexclusive/exclusive-fake-photos-in-myanmar-armys-true-news-book-onthe-rohingya-crisis-idUSKCN1LF2LB

Molaei, H. (2014). The Prospect of Civility in Indonesians' Online Polarised Political Discussions. Asian Journal of Communication, 24(5), 490-504. DOI: 10.1080/01292986.2014.917116.

Molaei, H. (2015). Discursive Opportunity Structure and the Contribution of Social Media to the Success of Social Movements in Indonesia. Information, Communication $\mathcal{E}$ Society, 18(1), 94-108. DOI: 10.1080/1369118X.2014.934388.

Morozov, E. (2011, January 15). Picking a Fight with Clay Shirky. Foreign Affairs. Retrieved from https:/foreignpolicy.com/2011/01/15/picking-a-fightwith-clay-shirky/

Newman, N., Dutton, W., \& Blank, G. (2012). Social Media and the Changing Ecology of News: The Fourth and Fifth Estates in Britain. International Journal of Internet Science. 7(1). pp. 6-22.

Nielsen. (2014, September 23). Online Video is Reshaping Southeast Asia's Media Landscape. Nielsen. Retrieved from https://www.nielsen.com/apac/en/insights/article/2014/online-videoreshaping-southeast-asian-media-landscape/ 
Nugroho, Y., \& Syarief, S. S. (2012). Beyond Click-Activism? New Media and Political Processes in Contemporary Indonesia. Berlin: Friedrich-Ebert-Stiftung and fesmedia Asia

Ong, J. C., \& Cabanes, J. V. A. (2018). Architects of Networked Disinformation: Behind the Scences of Troll Accounts and Fake News Production in the Philippines. Retrieved from http://newtontechfordev.com/wpcontent/uploads/2018/02/ARCHITECTS-OF-NETWORKED-

DISINFORMATION-FULL-REPORT.pdf

Ong, J. C., Tapsell, R., \& Curato, N. (2019). Tracking digital disinformation in the 2019 Philippine Midterm Election. Retrieved from https://www.newmandala.org/disinformation/

Ortiz, L., \& Rafanan, P. (2018, June 7). How Facebook's Rise Fueled Chaos and Confusion in Myanmar. Wired. Retrieved from https://www.wired.com/story/how-facebooks-rise-fueled-chaos-andconfusion-in-myanmar/

Paladino, B. (2018). Democracy Disconnected: Social Media's Caustic Influence on Southeast Asia's Fragile Republics. Washington, DC: Brookings Institution.

Palatino, M. (2014, June 5). Free Speech Under Attack in Southeast Asia. The Diplomat. Retrieved from http://thediplomat.com/2014/06/free-speechunder-attack-in-southeastasia/?allpages=yes\&print=yes

Patten, S. (2013). Assessing the Potential of New Social Media. Canadian Parliamentary Review, 36(2), 21-26.

Pertierra, R. (2012). The New Media, Society and Politics in the Philippines.. Berlin: Friedrich-Ebert-Stiftung and fesmedia Asia.

Quintos-de Jesus, M. (2012, January 31). Media in Southeast Asia. Speech delivered at the Seminar-Workshop Media Ownership Trends: Protecting and Promoting the Diversity of Media Platforms in Southeast Asia. Bangkok, Thailand. Retrieved from http://cmfrphil.org/inmediasres/melinda-de-jesus/media-in-southeast- asia-2/

Raicu, I. (2016, February 15). On the Ethics of Online Shaming. Recode. Retrieved from http://www.recode.net/2016/2/15/11587868/on-the-ethics-of-onlineshaming

Ressa, M. (2016, October 8). How Facebook Algorithms Impact Democracy. Rappler. Retrieved from https://www.rappler.com/newsbreak/148536facebook-algorithms-impact-democracy

Revesencio, J. (2015, May 4). Philippines: A Digital Lifestyle Capital in the Making? The Huffington Post. Retrieved from http://www.huffingtonpost.com/jonha-revesencio/philippines-a-digitallif_1_b_7199924.html?ncid=txtlnkusaolp00000592 
Ronson, J. (2015a, February 12). How One Stupid Tweet Ruined Justine Sacco's Life. The New York Times. Retrieved from http://www.nytimes.com/2015/02/15/magazine/how-one-stupid-tweetruined-justine-saccos-life.html?_r=0

Ronson, J. (2015b, June). When Online Shaming Goes Too Far. TED. Retrieved from

http://www.ted.com/talks/jon_ronson_what_happens_when_online_sha ming_spirals_out_of_control/transcript:?language=en

Safi, M., \& Hogan, L. (2018, April 3). Revealed: Facebook Hate Speech Exploded in Myanmar during Rohingya Crisis. The Guardian. Retrieved from https://www.theguardian.com/world/2018/apr/03/revealed-facebookhate-speech-exploded-in-myanmar-during-rohingya-crisis

Schumpeter, J. (1942). Capitalism, Socialism and Democracy. New York: Harper and Brothers.

Sinpeng, A. (2013). State Repression in Cyberspace: The Case of Thailand. Asian Politics and Policy, 5(3), 421-440.

Sison, S. (2015, October 15). What's Up with Smart Shaming? Rappler. Retrieved from http://www.rappler.com/views/ imho/109333-smart-shaming

Shirky, C. (2011, January/ February). The Political Power of Social Media. Foreign Affairs. Retrieved from https://www.foreignaffairs.com/articles/2010-1220/political-power-social-media

Soeriaatmadja, W. (2017, August 26). Indonesian Police Probe Alleged Fake News Factory's Protest Links. The Straits Times. Retrieved from https://www.straitstimes.com/asia/se-asia/indonesian-police-probealleged-fake-news-factorys-protest-links

Specia, M., \& Mozur, P. (2017, October 27). A War of Words Puts Facebook at the Center of Myanmar's Rohingya Crisis. The New York Times. Retrieved from https:/www.nytimes.com/2017/10/27/world/asia/myanmargovernment-facebook-rohingya.html

Sreekumar, T. T., \& Vadrevu, S. (2013). Online Political Memes and Youth Political Engagement in Singapore. Selected Papers of Internet Research, 14. Retrieved from https://pdfs.semanticscholar.org/0b75/6da39b881acd48a1cbcf6bea82dd37 6113f4.pdf

Stecklow, S. (2018, August 15). Why Facebook is Losing the War on Hate Speech in Myanmar. Reuters. Retrieved from https://www.reuters.com/investigates/special-report/myanmar-facebookhate/ 
Susanti, E. (2015). Hegemony of the Social Media Twitter About National Issues in Indonesia and its Implications to the Discourse Analysis Subject in Colleges. Tarbiya: Journal of Education in Muslim Society, 2(1), 153-166.

Tapsell, R. (2017a, February 17). Post-truth Politics in Southeast Asia. Inside Story. Retrieved from http://insidestory.org.au/post-truth-politics-in-southeastasia/

Tapsell, R. (2017b, September 25). If Indonesia Wants to Combat Hoaxes It Must Fix Its Public Broadcasters. Indonesia at Melbourne. Retrieved from https://indonesiaatmelbourne.unimelb.edu.au/if-indonesia-wants-tocombat-hoaxes-it-must-fix-its-public-broadcasters/

Tapsell, R. (2018, January 12). Disinformation and Democracy in Indonesia. New Mandala. Retrieved from https://www.newmandala.org/disinformationdemocracy-indonesia/

Taylor, A. (2014). The People's Platform: Taking Back Power and Culture in the Digital Age. New York: Picador

The Economist Intelligence Unit. (2019). Democracy Index 2019: A Year of Democratic Setbacks and Popular Protests. New York: The Economist.

The Straits Times. (2018, January 12). Indonesia Court Sentences Administrator of 'Fake News Factory' Saracen to Jail. The Straits Times. Retrieved from https://www.straitstimes.com/asia/se-asia/indonesia-court-sentencesadministrator-of-fake-news-factory-saracen-to-jail

Thornton, A. (2002). Does internet create democracy? Unpublished Master's Thesis, University of Technology Sydney. Retrieved from http://www.zip.com.au/ athornto//thesis1.htm

United Nations Human Rights Council. (2011, May 16). Report of the Special Rapporteur on the Promotion and Protection of the Right to Freedom of Opinion and Expression, Frank La Rue. United Nations General Assembly. Retrieved from https://www2.ohchr.org/english/bodies/hrcouncil/docs/17session/A.HRC. 17.27_en.pdf

Vadrevu, S., \& Lim, S. S. (2012). Youth, Politics and Social Media in Southeast Asia: Trends, Events and Implications. In W. Hofmeister (Ed.), Youth: Future Agents of Change or Guardians of Establishment? (pp. 19-28). Singapore: Konrad Adenauer Stiftung.

Vergara, R. A. Jr. (2016, January 30). Filipinos and Smart Shaming. The Varsitarian. Retrieved from http://varsitarian.net/opinion/20160130/filipinos_and_smart_shaming 
Wang, M. Y.-C. (2018, August 22). Disinformation in South East Asia: Governments as the Sources. gOv.news. https://g0v.news/disinformationin-south-east-asia-governments-as-the-sources-7da47c38cd54

Woolley, S. \& Gorbis, M. (2017, October 16). Social media bots threaten democracy. But we are not helpless. The Guardian. Retrieved from https://www.theguardian.com/commentisfree/2017/oct/16/bots-socialmedia-threaten-democracy-technology

Young, J., Swammy, P., \& Danks, D. (2018, December 15). Beyond AI: Responses to Hate Speech and Disinformation. Carnegie Mellon University. Retrieved from http://jessica-young.com/research/Beyond-AI-Responses-to-HateSpeech-and-Disinformation.pdf

Date Received: 8 January 2020

Date of Acceptance: 1 June 2020 